\title{
PATTERN OF CONTRACEPTIVE USE AMONG WOMEN OF DIFFERENT AGES: A HOSPITAL BASED STUDY
}

\author{
RAHMAN $\mathrm{J}^{1}$, SULTANA $\mathrm{N}^{2}$, NAZNEEN $\mathrm{K}^{3}$, WAHAB F ${ }^{4}$, WAZED $\mathrm{F}^{4}$, BEGUM HA ${ }^{5}$
}

\begin{abstract}
:
Background: Contraceptives not only prevent unplanned pregnancy but also enhance the quality of life. Choice of contraceptive varies from person to person.

Objectives: To observe the type of contraceptive chosen by women, to determine the sociodemographic status of women sought contraceptive and to detect the pattern of contraceptive selection by women of different age.

Methods: It was a cross sectional, observational, descriptive type of study performed at Family Planning Unit of Dhaka National Medical College Hospital, Dhaka, between May 2005 and April 2006. No sampling technique was applied in the study. All clients sought contraceptive methods were recruited for the study purposively. A total 3392 respondents was included in the study. The socio-demographic status and obstetrical history and choice of contraceptives of the clients were recorded and data were analysed.

Results: Age of the clients ranges between 16 to 49 years. Among the respondents 95.43\% were parous. The educational status showed $44.30 \%$ were illiterate and $48.23 \%, 5.02 \% 2.41 \%$ has got primary, secondary, higher secondary and above education respectively. Among the available methods of contraceptives of this Family Planning Unit, Injectable Depot Medroxy Progesterone Acetate (DMPA) and Combined Oral Contraceptive (COC) pill were chosen by $50.65 \%(n=1718)$ and $40.60 \%(n=1379)$ of respondents respectively. Intrauterine contraceptive Device (IUCD) and barrier method was chosen by $4.75 \%(n=160)$ and $3.98 \%(n=135)$ respondents respectively. It was observed that highest number of the clients was between the age 25 and 34 years. They were found at the top of using each type of contraceptive. The study reveals that a few older women ( $n=21)$ sought contraceptives and their choice of contraceptives were confined to COC and Barrier method only.
\end{abstract}

Key word: Contraceptives, women.

J Dhaka Med Coll. 2014; 23(1) : 109-113.

\section{Introduction:}

One of the most sensitive and intimate decisions made by an individual or by a couple is fertility control. It is often based on deeply held religious or rational convictions ${ }^{1}$. However, it must be recognized that there is considerable need for contraception ${ }^{2}$. Couples practice contraception for different personal reasons. Some have the intention to limit the family size; others desire to avoid childbearing because of the adverse effects on pre-existing illness on the pregnancy or vice versa ${ }^{3}$. As a matter of public policy some countries, especially those that are least developed, promote contraception in an effort to curtail undesired population growth ${ }^{4}$. Bangladesh is

1. Dr. Jahanara Rahman, Associate Professor, Department of Obstetrics \& Gynaecology, Dhaka National Medical College, Dhaka.

2. Dr. Nasreen Sultana, Associate Professor, Department of Obstetrics \& Gynaecology, Dhaka National Medical College, Dhaka.

3. Prof. Khadiza Nazneen, Professor \& Head, Department of Obstetrics \& Gynaecology, Enam Medical College, Savar, Dhaka.

4. Dr. Farhana Wahab, Lecturer, Community Medicine, Dhaka Medical College, Dhaka

5. Dr. Feroza Wazed, Associate Professor, Department of Obstetrics \& Gynaecology, Dhaka Medical College, Dhaka.

6. Prof. Hosne Ara Begum, Professor \& Head, Department of Obstetrics \& Gynaecology, Dhaka National Medical College, Dhaka.

Correspondence: Dr. Jahanara Rahman, Associate Professor, Department of Obstetrics \& Gynaecology, Dhaka National Medical College, Dhaka, Email: jahanararahman64@gmail.com Cell Phone: +8801819239259. 
a densely populated country. Fertility in Bangladesh has been declining since the 1970s. Between 2007 and 2011 the decline in fertility was greater in urban areas compared to the rural areas. Bangladesh's current health sector program, the Health, Population and Nutrition Sector Development Program (HPNSDP) 2011-2016 aims to reduce fertility to 2 births per woman by 2016. Overall, 61 percent of currently married women in Bangladesh are currently using a contraceptive method. Among the contraceptives combined oral pill is by far the most widely used method (27\%), followed by Injectable contraceptives (11\%), female sterilization (5\%), and condoms $(6 \%)$. Rest one percent adopted male sterilization, IUDs, and implants. There is little variation overall in contraceptive use by women's education level and wealth quintile ${ }^{5}$.

Little attention has been paid to the contraceptive needs of the older women. With the advancing age there is decreased fertility, but still there is chance of pregnancy. Pregnancy at this age has increased risks and complications for both mother and foetus ${ }^{6}$.

\section{Materials and method:}

It was a cross-sectional, observational study carried out at the Family Planning unit of Dhaka National Medical College Hospital between May 2005 and April 2006. Objectives of the study were to observe the type of contraceptive chosen by women, to determine the socio-demographic status of women sought contraceptive and to detect the pattern of contraceptive selection by women of different age. No sampling technique was applied in the study. All clients sought contraceptive methods were recruited for the study purposively. Total population was divided into four age groups: (16to 24) years, (25 to 34) years, (35 to44) years and 45years and above. Contraceptive chosen by these clients among the four methods available in this family planning unit: Combined Oral Contraceptive pills (COC), Injectable contraceptive - Depot Medroxy progesterone acetate (DMPA), Intra-uterine contraceptive method (IUCD) -copper $\mathrm{T}$ and barrier method (condom) were recorded. The socio-demographic status and obstetrical history were also recorded.

\section{Results:}

A total 3392 clients were included in the study. Age of the clients ranges between 16 and 49 years. Majority (63\%) of the population were in the age group of 25 to 34years. Other $8 \%(n=262)$, $28 \%(\mathrm{n}=953)$ and $1 \%(\mathrm{n}=21)$ were (16 to 24$)$ years, (35 to 44) years and e"45 years of age group respectively. More than 95\% were parous and $4.57 \%$ were nulliparous. The educational status showed $44.30 \%$ were illiterate and $48.23 \%$, $5.02 \% 2.41 \%$ has got primary, secondary, higher secondary and above education respectively. Among the available methods of contraceptives, Injectable Depot Medroxy Progesterone Acetate (DMPA) and Combined Oral Contraceptive (COC) pill were chosen by $50.65 \%(n=1718)$ and $40.60 \%$ $(n=1379)$ of respondents respectively. Intrauterine contraceptive Device (IUCD) and Barrier method was chosen by $4.75 \%(n=160)$ and $3.98 \%(n=135)$ respondents respectively. The study found $84.73 \%(n=222)$ clients of the age 16 to 24 years chose COC.A few of them took barrier $(n=20)$ and IUCD $(n=20)$, but none of them took Injectable contraceptive. It was also observed that $57.80 \%(n=1245)$ clients of the age group 25 to 34 years chose Inj contraceptives. Among the rest $35.39 \%, 3.38 \%$ and $3.47 \%$ chose $\mathrm{COC}$, barrier method and IUCD respectively. We found $50 \%(n=473)$ clients of 35 to 44 years age group sought Inj. DMPA as contraceptives. Others of this age group chose $\mathrm{COC}$, barrier and IUCD 39\%, 4\% and 7\% respectively. The elder clients of 45years and above age were least in number seeking contraceptive. Their choice of contraceptive was limited to Combined oral contraceptive pill $(n=19)$ and barrier method $(n=2)$ only. The study revealed majority of the clients' age ranges 25 to 34 years and they were at the top of all age group adopting each type of contraceptive method.

\section{Results:}

Distribution of respondents according to age

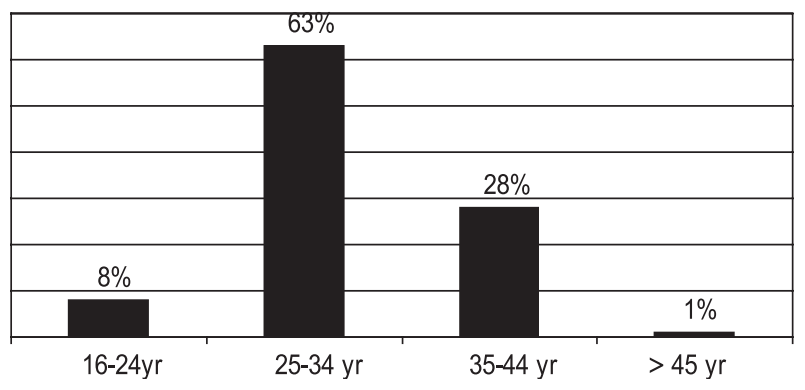

Fig.-1 


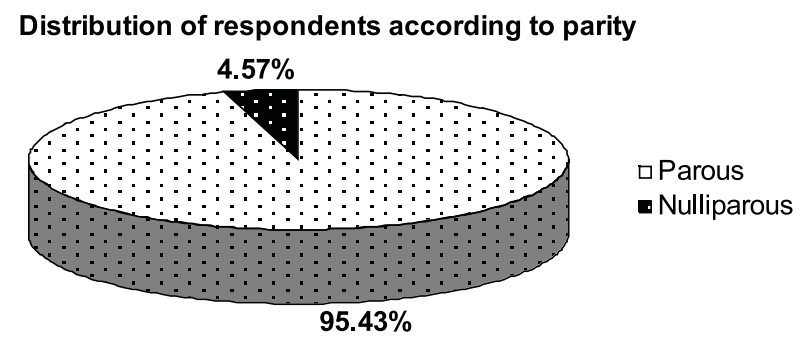

Fig.-2

Distribution of respondents according to level of education

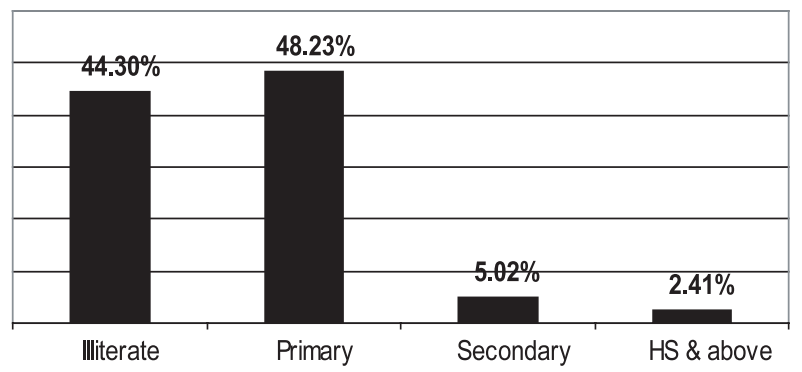

Fig.-3

Distribution of respondents according to contraceptive use
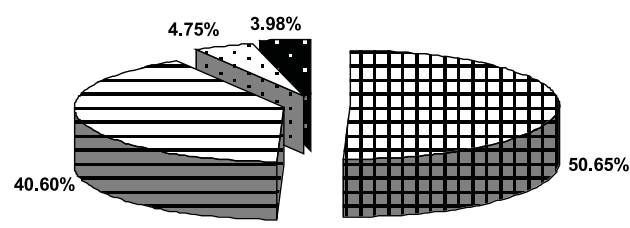

IDMPA

BCOC

口IUCD

Barrier

Fig.-4

Table-I

Distribution of respondents according to age group vs contraceptive use

\begin{tabular}{lcccc}
\hline $\begin{array}{l}\text { Age } \\
\text { (in years) }\end{array}$ & COC & Inj. & $\begin{array}{c}\text { Barrier } \\
\text { Contraceptive }\end{array}$ & IUCD \\
\hline $16-24$ & 222 & 0 & 20 & 20 \\
$25-34$ & 763 & 1245 & 73 & 75 \\
$35-44$ & 375 & 473 & 40 & 65 \\
45 and above & 19 & 0 & 2 & 0 \\
\hline
\end{tabular}

Eighty four percent respondents of the youngest group (16-24 years) chose COC which was significantly higher than the percentage of Barrier method ( $p$ value- 0.0000 ) or IUCD ( $p$ value- 0.0000 ) users and it was statistically highly significant. On the other hand, majority of the respondents of age 25 to 34 years chose Injectable DMPA. The second choice of contraceptive by this age group was COC. But the percentage of clients chose Inj contraceptive was significantly higher than that of COC and was statistically highly significant ( $p$ value 0.0000 ).

\section{Discussion:}

This hospital-based study was carried out to get information regarding the pattern of contraceptive use among the women of different ages. To know the real picture a community-based study was necessary. However this could present a picture of hospital setting.

In this study we found most of clients (95.43\%) were parous (fig-2). Actually, multiparous women desires to limit their family size and spaced child births and are more interested in using contraceptive than nulliparous.

Current study showed $55.7 \%$ and $44.3 \%$ respondents were literate and illiterate respectively (fig-3). It revealed literate women were a bit higher in number than illiterates using contraceptives, but the difference were not significant. Another study in Bangladesh found women seeking contraceptive in family planning center were $49 \%$ literate which was similar to our finding ${ }^{7}$.

We found that age of majority (63.56\%) of the respondents was between 25 and 34years (Table-I). Women of age 35 to 44 years were second highest in percentage (28\%) using contraceptives. Respondents of age group 16 to 24 years were very few (8\%) and women of age 45 and above were negligible in number (1\%). We found the percentage of women of age 25 to 34 years was significantly higher in comparison to the women of age 35-44 years which was statistically highly significant $(\mathrm{p}$ value 0.0000 ). Wellings and coworkers also found the highest number of women using contraceptives were late twenties and early thirties. $^{8}$

This study found that hormonal contraceptives were chosen by majority of the population. Similar result was noticed in a study on rural population of Bangladesh ${ }^{7}$. A study of USA also showed that use of hormonal contraceptive is increased in recent years with the advent of 
new options ${ }^{9}$. According to a study COC was the highest used hormonal contraceptive ${ }^{10}$. Whereas our study found Inj DMPA was chosen by higher percentage of women $(50.65 \%)$ than COC $(40.60 \%)$. The cause of this dissimilarity is probably the easy availability of $\mathrm{COC}$ in medicine or general shops of Bangladesh for which women need not to come to the Family Planning centre to avail COC. Again, about 50\% of our study population was illiterate and they prefer DMPA than COC as it needs no calculation and daily intake is not necessary.

Present study found few clients $(4.75 \%)$ adopted IUCD which was significantly lower in number in comparison to COC and Inj DMPA user. But another author found significant number of the women using IUCD ${ }^{11}$. Our clients avoided this method may be due to religious ground. Moreover illiterate people have fear of a foreign body in uterus and its side effects might have an impact on this.

Lowest percentage (3.98\%) of the population of this study took barrier method. Probably due to cheap and easy availability of this contraceptive, clients do not go to the family planning center to collect this rather they buy it from general shops. Another author also showed that negligible number of clients sought barrier method in family planning center ${ }^{7}$.

The study found choice of contraceptive differs according to age. Majority of the clients of 16 to 24 years of age chose COC than other available contraceptives ( $p$ value-0.000). But in a study of Iran, IUCD was found as the commonest contraceptive for this age ${ }^{12}$. It differs from ours, because most of our clients of this age group were nulliparous and in our country nulliparous patients are not given IUCDs.

It was observed that the respondents of age (25 to 34 ) years and (35 to 44) years chose Inj DMPA in higher percentage than COC ( $p$ value 0.000 and $p$ value 0.0000 respectively). But another study found IUCD was the commonest contraceptive used by this age ${ }^{12}$. Side effects of the device and religious ground are thought to be the possible causes of less use of IUCD in our study.
We found a few number $(n=21)$ of elder women (age 45 years or more) came to our Family planning Unit seeking contraceptive. But Wellings and coworkers got a higher number of elderly using contraceptives. This dissimilarity was probably due to ignorance and lack of knowledge about suitable contraceptive for women of elder age in our country. But no doubt, world wide contraceptive practice by women of elder age group is lower in comparison to that of younger age. This is because the women of perimenopausal age often believe that their fertility has ceased due to menstrual irregularity and consequently they stop using contraception. ${ }^{13}$.

\section{Conclusion:}

Women and couples use contraceptives to have healthier pregnancies, to help time and space births, and to achieve their desired family size. The choice of contraceptive is very personal one. This study showed that choice of contraceptive varies among women of different age. Women's choice of a contraceptive is influenced not only by their personal characteristics but also by their assessments of available options. Though combined oral pill is the most popular contraceptive in this country, Injectable contraceptive was chosen by majority of the population of this study. Actually one can get combined oral pill and barrier method from pharmacy or general shop and need not to come to family planning center. Due to the side effects of IUCD, it is not chosen by many of this population. This family planning centre does not provide implants which is available in many family planning centers of Bangladesh. Older women were very few in number seeking contraceptives and majority of the older women chose COC.

To get a real picture community based study is needed. Family planning has well-documented health benefits for mothers, newborns, families and communities. Many women of our country do not know which ones are suitable for them. It is clinician's duty to help women to choose a suitable contraceptive regarding their age, parity and health. 


\section{References:}

1. Knopp RH, LaRosa JC, Burkman RT. Contraception and dyslipidemia. Am J Obstet Gynecol 1993; 6(2): 1994.

2. Kubba A, et al. Contraception. Lancet 2000; 356: 1913.

3. Loriaux DL, Wild RA. Contraceptive choices for women with endocrine complications. Am J Obstet Gynecol 1993; 168: 2021.

4. Martin JA, Hamiltion BE, Ventura SJ. Births: Preliminary data for 2000. Natl Vital Stat Rep 2001; 49:1.

5. Bangladesh Demography and Health Survey, 2011.

6. Navot D, Drews MR, Bergh PA, et al. Age-related decline in female fertility is not due to diminished capacity of the uterus to sustain embryo implantation. Fertil Steril 1994; 61: 97-101.

7. Nasreen A, Biswas MH.A Study on pattern of contraceptive use among the women upto 45 years of age in Chowara Union under Sadar Thana of Comilla District. Bangladesh Private Med Pract J 2002; 8(1): .
8. Wellings K, Field J, Johnson A, Wadsworth J. Sexual behaviour in Britain: the national survey of sexual attitudes and lifestyles. London: Penguin Books Ltd; 1994.

9. Daniels K, Mosher WD, Jones. Contraceptive methods women have ever used: United States, 1982-2010, National Health Statistics Reports, 2013, No. 62.

10. Contraceptive Method Choice. Method use among US women who practice contraception, 2010.www.guttmacher.org (accessed on 20. 11. 2013).

11. Finer LB, Jerman J, Kavanaugh ML, Changes in use of long-acting contraceptive methods in the United States, 2007-2009, Fertil Steril 2012;

12. Nazarpour SO, Azimi H. Study of the rate of using family planning methods and attitudes of married women under 25 years referring to healthtreatment centers about family planning in west of Mazandaran province during 2001. www.Gendermedicine.com. (Accessed on 16. 12. 2013).

13. Burkman RT, al. Transitional management: the use of oral contraceptives in perimenopause. (Accessed on 11.11.2013). 